\title{
Preparation of Silicon Oxycarbide Composites Toughened by Inorganic Fibers via Pyrolysis of Precursor Siloxane Composites
}

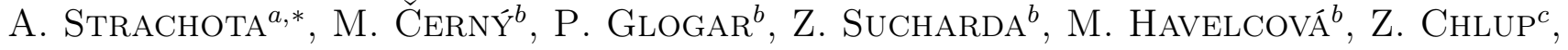 \\ I. DlOUhÝ ${ }^{c}$ AND V. KOZÁK ${ }^{c}$ \\ ${ }^{a}$ Institute of Macromolecular Chemistry, Academy of Sciences of the Czech Republic, v.v.i. \\ Heyrovskeho namesti 2, CZ-16200 Praha, Czech Republic \\ ${ }^{b}$ Institute of Rock Structure and Mechanics, Academy of Sciences of the Czech Republic, v.v.i. \\ V Holesovickach 41, CZ-182 09, Praha, Czech Republic \\ ${ }^{c}$ Institute of Physics of Materials of the Academy of Sciences of the Czech Republic, v.v.i. \\ Zizkova 22, CZ-61662 Brno, Czech Republic
}

The optimization of silicon oxycarbide (SiOC) synthesis (sol-gel/pyrolysis) is described, starting from methyltriethoxysilane, dimethyldiethoxysilane, tetraethoxysilane, ethyltriethoxysilane and propyltriethoxysilane. Variation of final elemental composition was tested via change of monomer ratios and combinations. The main aim was to achieve low weight losses during cure and pyrolysis and high micromechanical properties. Gas chromatography and mass spectroscopy was used to analyse the by-products of cure and pyrolysis, indicating a prominent role of cyclosiloxane and polyhedral oligomeric silsesquioxane (POSS) oligomers. Best results were obtained with high contents of methyltriethoxysilane in the monomers mixture.

PACS: 81.05.Je, 81.05.Mh, 82.30.Lp

\section{Introduction}

Silicon oxycarbide ( $\mathrm{SiOC}$ ) is a hard glass which is structurally related to both silica $\left(\mathrm{SiO}_{2}\right)$ and silicon carbide ( $\mathrm{SiC})$. It enjoys a considerable research interest, because of its high mechanical properties and refractoriness [1], interesting viscoelastic behavior at elevated temperatures [1], and not least because of an improved oxidation resistance [2-5] in comparison to $\mathrm{SiC}$, due to much more efficient surface passivation with $\mathrm{SiO}_{2}$.

$\left[\mathrm{CH}_{3} \mathrm{SiO}_{1.5}\right]_{n} \rightarrow \mathrm{SiO}_{x} \mathrm{C}_{y}+\mathrm{H}_{2}+\mathrm{C}_{x} \mathrm{H}_{y}+$ oligo(siloxane)

Scheme 1: Preparation of SiOC via siloxane pyrolysis

Attractive is the easy accessibility of SiOC via pyrolysis of siloxane resins (Scheme 1, review [6]. Even ideally homogeneous $\mathrm{SiOC}$ can be considered a nanocomposite, consisting of $\mathrm{SiO}_{2}$ - and SiC-like structural units, as illustrated in Scheme 2. The highest SiOC homogeneity is achieved via magnetron sputtering $[7,8]$. Above $1100^{\circ} \mathrm{C}$, $\mathrm{SiOC}$ undergoes a "micro"-phase separation into larger nanometric domains of $\mathrm{SiC}$ embedded in $\mathrm{SiO}_{2}$ [1, 9-12]. Typical SiOC also contains turbostratic graphite [1, 4, 9] which is responsible for its black color. Only under special synthesis conditions, completely graphite-free, colorless SiOC can be prepared [13]. SiOC synthesis via

\footnotetext{
* corresponding author; e-mail: strachota@imc.cas.cz
}

pyrolysis typically leads to porous products, so that it is difficult to obtain large, well-shaped, monolithic pieces.

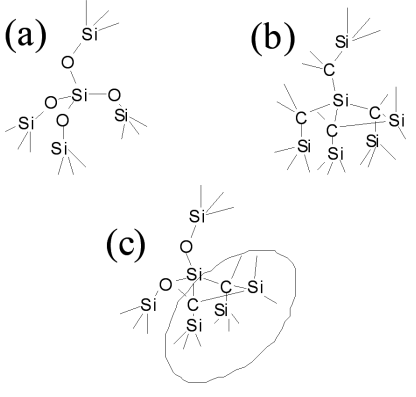

Scheme 2: Symbolic representation of $\mathrm{SiO}_{2}$ (a), of the denser $\mathrm{SiC}(\mathrm{b})$ and of $\mathrm{SiOC}$ (c) covalent networks

In previous work the authors prepared compact SiOC composites with silicate fibers, using commercial siloxane resins (repeated soaking/pyrolysis) [14-16]. It was demonstrated [17] that high amounts of iron oxide in the fibers (basalt) lead to their good pull-out behavior. Micromechanical properties of SiOC were also recently investigated [18]. In this work the focus was of nonexpensive variation and optimization of $\mathrm{SiOC}$ synthesis using common alkoxysilanes as starting compounds. 


\section{Experimental}

\subsection{Chemicals}

Methyltriethoxysilane,

dimethyldiethoxysilane, tetraethoxysilane, ethyltriethoxysilane and propyltriethoxysilane, as well as catalyst sulfuric acid $\left(\mathrm{H}_{2} \mathrm{SO}_{4}\right.$ $98 \%$ ), sodium hydrogen carbonate and toluene were purchased from Sigma-Aldrich and used without further purification.

\subsection{Synthesis of precursor resins}

$4 \mathrm{wt} \% \mathrm{H}_{2} \mathrm{SO}_{4}$ in water was mixed with the alkoxysilane monomers so that the ratio $\mathrm{H}_{2} \mathrm{O} / \mathrm{OR}(\mathrm{OR}=$ alkoxy groups from alkoxysilanes) was equal $2.25,1.5$ and 3 . The mixture was stirred for 5 min without heating (complete homogenization and heat evolution is observed), thereafter it was stirred for $25 \mathrm{~min}$ on a heating plate at $130{ }^{\circ} \mathrm{C}$ (evaporation of formed ethanol and of excess- and condensation-water). Finally, the raw (liquid) product was diluted by toluene to $50 \mathrm{wt} \%$, and $\mathrm{H}_{2} \mathrm{SO}_{4}$ was neutralised with $\mathrm{NaHCO}_{3}$ (10\% excess). The toluenic resin solution was separated from the small aqueous phase formed from $\mathrm{H}_{2} \mathrm{SO}_{4}$ and $\mathrm{NaHCO}_{3}$ and stored in refrigerator.

\subsection{Resin cure and pyrolysis}

Resin solutions were put into a porcelain weigh dish and first evaporated under air stream at room temperature around $15 \mathrm{~min}$, yielding a viscous paste. This was further dried under vacuum at room temperature for two hours, yielding dry non-cured resin (weight determination). For cure, the resins were heated on air at $90^{\circ} \mathrm{C} / \mathrm{h}$ up to $250^{\circ} \mathrm{C}$, and thereafter this temperature held constant for $4 \mathrm{~h}$. The pyrolysis of the cured siloxanes to $\mathrm{SiOC}$ was carried out under nitrogen atmosphere by heating from 250 to $420^{\circ} \mathrm{C}$ at $50^{\circ} \mathrm{C} / \mathrm{h}$, followed by slower heating from $420^{\circ} \mathrm{C}$ till $1000^{\circ} \mathrm{C}$ at $10^{\circ} \mathrm{C} / \mathrm{h}$. The cooling of the finished SiOC sample was performed at $50^{\circ} \mathrm{C} / \mathrm{h}$.

\subsection{Weight Loss determination}

The weight loss of samples after curing, or after curing and subsequent pyrolysis was measured by weighing larger specimens $(2 \mathrm{~g})$ on an analytical balance, before and after the respective heating program, averages of five values were used. For recording thermogravimetric massloss vs. temperature curves (TGA) a Kern $E W$ device was used, at a heating rate $90^{\circ} \mathrm{C} / \mathrm{h}$, with air as purge gas.

\subsection{Pyrolysis / Gas Chromatography / Mass Spectroscopy analysis}

The cure and pyrolysis was followed using a Trace$D S Q I I$ gas chromatograph (GC) with quadrupole mass spectrometer from ThermoElectron, equipped with the $C D S$ Pyrobrobe 5000 pyrolysis chamber. For every pyrolysis-GC-MS analysis, $2 \mathrm{mg}$ of a powdered sample were used. The pyrolysis was carried out in helium atmosphere for $30 \mathrm{~s}$, at 160, 200, 250, 300, 400, 500, 650, 750 and $1000^{\circ} \mathrm{C}$. The silica column $T R-5 M S$ with a moderately polar stationary phase was used for GC: Injection temperature was $250^{\circ} \mathrm{C}$, mobile phase (helium) flow: $1.5 \mathrm{~mL} / \mathrm{min}$, injection splitting was $1: 10$, GC program: initial temperature: $35^{\circ} \mathrm{C}$, rate $5^{\circ} \mathrm{C} / \mathrm{min}$, final $T$ : $300{ }^{\circ} \mathrm{C}$. Product mass spectra were assigned using a NIST library.

\subsection{Micromechanical testing}

The micromechanical analysis of SiOC samples was performed using a ZWICK Z2.5 indentation tester, equipped with the micro hardness head ZHU0.2 (200 N load cell). The depth measurement resolution was $20 \mathrm{~nm}$. Experiments (repeated five times) were performed at $2 \mathrm{~N}$ peak load, and in accordance with the Vickers hardness test standard [19]. The unloading branch of loading curves (force vs. indentation depth) yielded the universal hardness HMs and the indentation elastic modulus $E_{I T}$. The indents were also measured optically using a laser confocal microcope LEXT OLS3100 (Olympus, Japan), yielding Vickers hardness HV02.

\section{Results and discussion}

\subsection{SiOC Synthesis procedure}

Several alkoxysilane monomers (Scheme 3), were tested in a well-controlled sol-gel synthesis of siloxane precursors to silicon oxycarbide ( $\mathrm{SiOC}$ ).

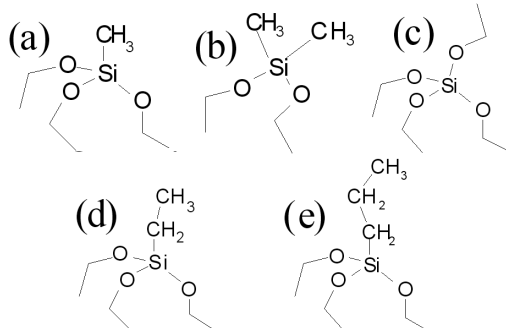

Scheme 3: Monomers: (a) = methyltriethoxysilane, "T", (b) = dimethyldiethoxysilane, "D", (c) = tetraethoxysilane, "Q", (d) = ethyltriethoxysilane, "TEt", (e) = propyltriethoxysilane, "TPr"

The SiOC preparation consisted of three steps (Scheme 4): (1) First, alkoxysilane monomers were subjected to an acid-catalyzed sol-gel process with water (hydrolysis followed by gradual Si-OH group condensation to Si-O$\mathrm{Si}$ ), under heating and evaporation of the formed alcohol. $\mathrm{OH}$-functional oligomeric siloxane resins were obtained, whose further condensation was stopped by catalyst neutralization and by dilution with toluene to a storable $50 \%$ solution (well suited for fiber textures impregnation); (2) In the second step, the precursor solution was dried and subsequently cured at $250{ }^{\circ} \mathrm{C}$ to yield an infinite network; (3) Finally, the cured polysiloxane was pyrolysed at $1000^{\circ}$ Cunder nitrogen to yield SiOC. 


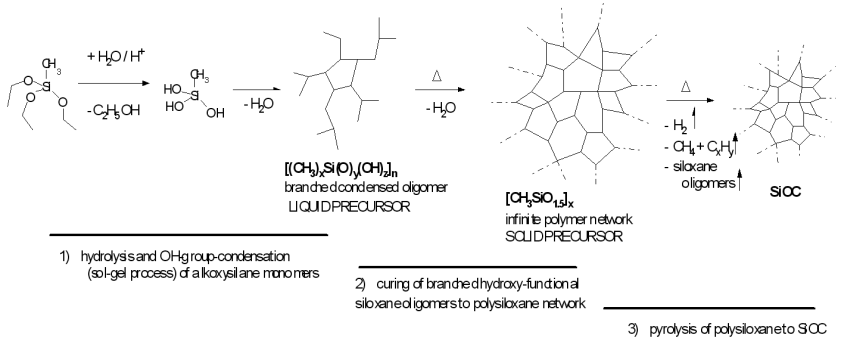

Scheme 4: The employed preparative path to SiOC.

\subsubsection{The examination of the sol-gel step}

The effect of the amount of added water in step (1) of Scheme 4 was studied first: lower than stoichiometric amount leads to an incomplete hydrolysis of the alkoxysilane. Until $\mathrm{H}_{2} \mathrm{O}$ : OR ratio of 0.5 , a complete subsequent cure to perfect polysiloxane is still possible (via OH-OR condensation), but the steps (1) and (2) of Scheme 4 proceed slower, which could be eventually an advantage (improved control of gas evolution and solidification). $\mathrm{H}_{2} \mathrm{O}$ :OR ratios of 1.5 (low), 2.25 and 3 (high excess) were tested, taking into account evaporation losses $(50 \%)$ of water. The $\mathrm{H}_{2} \mathrm{O}$ :OR ratio of 2.25 led to optimal curing behavior and was selected as standard. Optimal reaction time for the sol-gel step (1) is around $70 \%$ of the time of gelation. At lower conversions, the resins foam during cure (usually not desired). At higher conversions, the resin storability becomes problematic.

\subsection{Weight loss of the siloxane resins during cure and pyrolysis}

Weight losses during cure and pyrolysis are illustrated in Figs. 1-3: Fig. 1 depicts a typical behavior during cure $\left(\right.$ at $90^{\circ} \mathrm{C} / \mathrm{h}$ ). After the first scan, practically no loss occurs during the second, until $270^{\circ} \mathrm{C}$. Above this temperature, weight loss is observed in any scan, indicating the start of pyrolysis reactions (strong above $400{ }^{\circ} \mathrm{C}$ ). The obtained resins were compared with the commercial methylsiloxane "M130" from Lucebni zavody a.s. Kolin, Czech Republic (loss after cure and pyrolysis: 20\%).

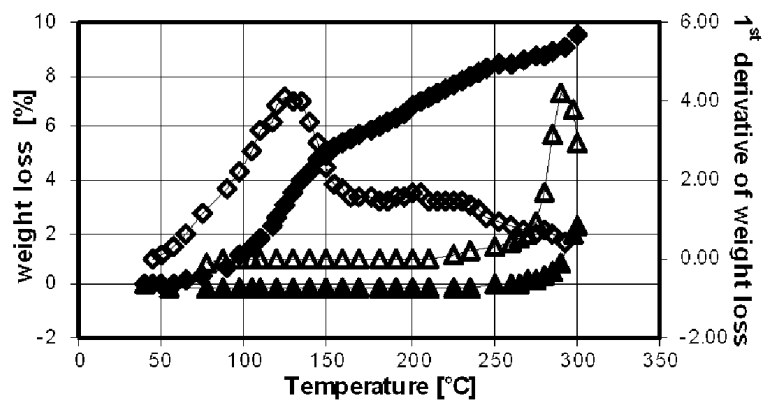

Fig. 1. Exemplary weight loss behavior during siloxane cure and the onset of pyrolysis near $300^{\circ} \mathrm{C}$ : full squares: first heating, hollow squares: derivative of the weight loss, full triangles: second heating, hollow triangles: derivative of weight loss for second heating.

As illustrated in Figs. 2 and 3, the weight losses during cure step and during pyrolysis step are similar in the

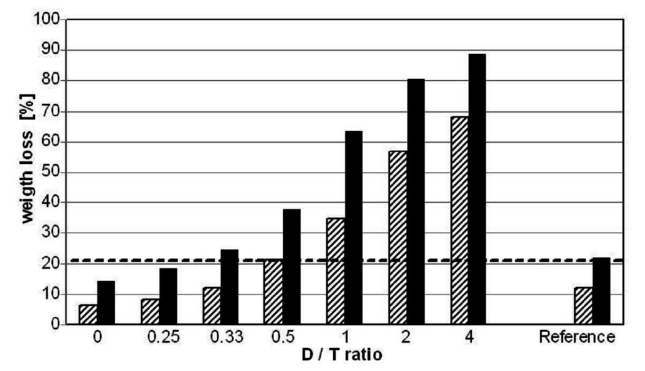

Fig. 2. Effect of bifunctional carbon-rich "D"-monomer content on the weight loss behavior of siloxane resins based on methyltriethoxysilane (trifunctional, "T") and dimethyldiethoxysilane (bifunctional, "D").

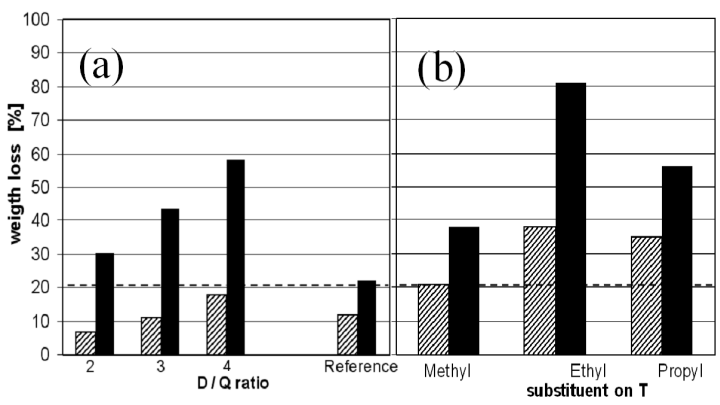

Fig. 3. (a) Effect of bifunctional carbon-rich "D"monomer content on the weight loss behavior of siloxane resins based on tetraethoxysilane (tetrafunctional, "Q") and dimethyldiethoxysilane (bifunctional, "D"), (b) Effect of size of the alkyl substituent on triethoxysilane units "T", onto the weight loss of T2D1 resins.

best resins. In those with high weight losses, most of the loss often occurs already during the cure. Generally, high content of the carbon-rich repeat units "D" (from dimethyldiethoxysilane) leads to high losses.

In the series methyltriethoxysilane/ dimethyldiethoxysilane $(T / D)$ (Fig. 2), the resins with "D" "T" (Scheme 3) monomer ratios 0, 0.25 and 0.33 display smaller (or same) weight losses than the reference. The resin with $D / T=0$ has a very strong tendency to gelation, so that $\mathrm{D} / T=0.25$ ("T4D1") was ideal. The resins with $D / T=0.5$ to 4 display high losses, which increase with D content (suspected elimination of cyclic D oligomers - confirmed by $G C / M S$ below). The $Q / D$ series (Fig. 3a), in which the "T"-monomer was replaced by the cheaper and carbon-free tetraethoxysilane, "Q" (Scheme 3), showed very promising low weight losses at cure, especially for $D / Q=2$ and 3. Q1D2 had a high tendency to gelation, while Q1D3 is unproblematic. Unfortunately, all the $Q / D$ resins display too high $D$-losses at pyrolysis. 


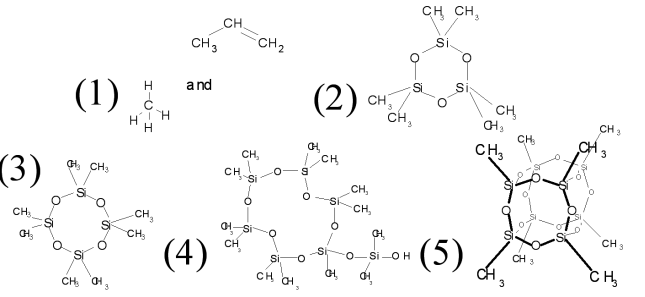

Scheme 5: Assignment of important components of pyrolysis gases from gas chromatograms via coupling with mass spectroscopy

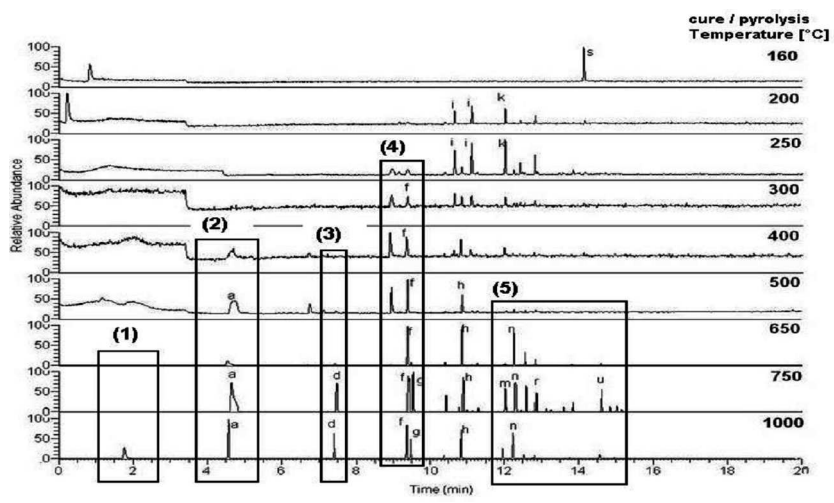

Fig. 4. Gas chromatograms of gases escaping during the cure of siloxane resins and their pyrolysis to SiOC.

Effect of alkyl groups on "T" (trialkoxysilane) monomer on weight loss (Fig. $3 \mathrm{~b}$ ): The variation of $\mathrm{Si} / \mathrm{O} / \mathrm{C}$ ratios via "D" (carbon-rich dimethyldiethoxysilane) content in the $T / D$ and $Q / D$ series was found to be rather small, due to strong elimination of $D$. Hence, the variation of carbon content was tested by introducing larger alkyl substituents on "T". Larger alkyl groups on $T$ lead to higher losses than the methyl groups, but the trend is not simple (Fig. 3 b): Ethyl groups cause a twofold increase in weight loss, if compared with methylated T2D1. n-Propyl groups yield a much better result, but the total loss is still higher by $30 \%$. Obviously, the larger alkyl substituents favor the formation of volatile oligomers of $T$ (see GC/MS below). With increasing substituent size (n-propyl), radical crosslinking and carbonization of these substituents reverse the $T$-release trend. A butyl group could possibly achieve improved weight losses, but reactive larger groups on $T$ seem to be more promising.

\section{3. $G C$-MS-study of pyrolysis by-products}

The evolution of gaseous by-products during cure and pyrolysis of precursor siloxane resins was followed via gas chromatography coupled with mass spectroscopy (GC/MS). Figure 4 shows chromatograms of fumes evolving from a T2D1 sample pyrolysed at $T=160^{\circ} \mathrm{C}$ to $1000{ }^{\circ} \mathrm{C}$ ("T" corresponds to methyltriethoxysilane, "D" to dimethyldiethoxysilane monomer, the numbers give monomer ratios). Products marked in Fig. 4 were assigned via $M S$ (Scheme 5). "D"-unit content led to release of cyclic $D$-trimer (highly preferred) and $D$-tetramer (marked as (2) and (3), boiling points: $134^{\circ} \mathrm{C}$ and $176^{\circ} \mathrm{C}$, respectively). D-rich resins (T1D1, T1D2, T1D4, Q1D4 $(Q=$ tetraethoxysilane $))$ release cyclo-D3 and -D4 already during cure, indicating their formation during synthesis. Above $400{ }^{\circ} \mathrm{C}$, cyclo-D evolves due to pyrolysis (see literature $[20,21]$ ). Above $400^{\circ} \mathrm{C}$, methane and propene were detected (marked (1)), as side products of alkyl substituents pyrolysis. From moderate pyrolysis temperatures $\left(300^{\circ} \mathrm{C}\right)$ onwards, branched cyclic $D-T$ oligomers marked as (4) were detected. Above $650{ }^{\circ} \mathrm{C}$, spherical T-oligomers (POSS, marked (5)) evolve, especially strongly if ethyl-substituted " $T$ " was used.

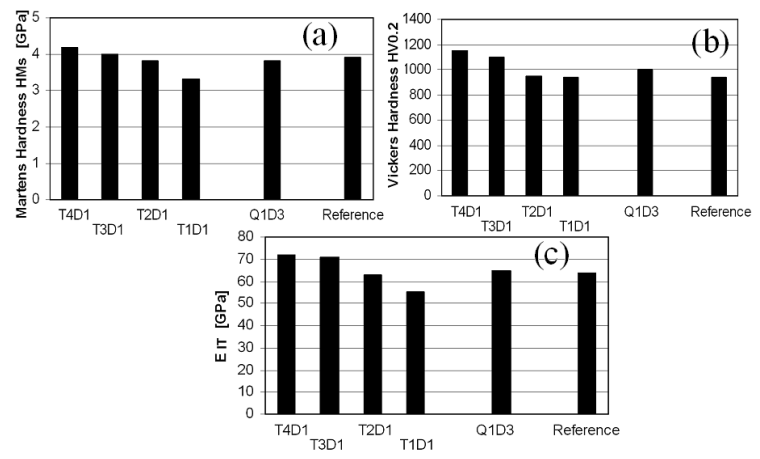

Fig. 5. Micromechanical characteristics of $\mathrm{SiOC}$ glasses in dependence of monomer composition: (a) Martens hardness HMs, (b) Vickers hardness HV0.2, (c) indentation Young modulus $E_{I T}$, "T" corresponds to methyltriethoxysilane, "Q" to tetraethoxysilane, and "D" to dimethyldiethoxysilane, numbers to monomer ratios.

\subsection{Micromechanical testing}

The quality of the SiOC glasses prepared was evaluated via micro-indentation. Regarding precursor composition, the mechanical properties showed similar but much weaker trends like weight losses. In Fig. 5, the Martens hardness HMs (a), the Vickers hardness HV0.2 (b) and the indentation Young modulus $E_{I T}$ are compared for SiOC made from T4D1, T3D1, T2D1, T1D1, Q1D3 and from the reference"M130". The series T4D1 to T1D1 shows a moderate but clear decrease of hardness and modulus with increasing $\mathrm{D}$ content. This trend seems to correlate more with density, rather than with composition, because samples with high weight losses were typically micro-porous ("micro-foaming"). Densities, determined by weighing thoroughly powdered samples on air and in water (after being soaked for one day), range from 2.0 to $1.8 \mathrm{~g} / \mathrm{mL}$ for T4D1 to T1D1 (before pyrolysis: $1.2 \mathrm{~g} / \mathrm{mL}$ ). Interestingly, Q1D3 displays nearly the same micromechanical properties like SiOC from the reference, in spite of Q1D3 relatively high weight loss. 


\section{Conclusions}

Silicon oxycarbide (SiOC) glasses with varying element ratio were prepared from mixtures of alkoxysilane comonomers. Combining simple monomers, linear carbonrich dimethyldiethoxysilane with branching carbon-poor ones (methyltriethoxysilane or tetraethoxysilane) led to rather narrow variation of final SiOC composition, due to dimethyldiethoxysilane elimination upon pyrolysis. Samples with high weight losses were micro-porous. Larger alkyl groups on triethoxysilane units led to formation of volatile cage-like silsesquioxane oligomers, but also to higher substituent carbonization, hence large and polymerizable substituents on trialkoxysilane units seem to be most promising for future work.

\section{Acknowledgments}

The authors thank Eva Miškovská for the preparation of the larger resin batches, and the Grant Agency of the Czech Republic, Grant Nr. 106/09/1101 for the financial support.

\section{References}

[1] H.J. Kleebe, Y.D. Blum, J. Europ. Ceramic Society 28, 1037( 2008).

[2] M. Narisawa, R. Sumimoto, K. Kita, J. Mater. Sci. 45, 5642 (2010).

[3] G.M. Renlund, S. Prochazka, R.H. Doremus, J. Mater. Res6, 2716 (1991).

[4] F. Kolar, V. Machovic, J. Svitilova, L. Borecka, Mater. Chem. Phys. 86, 88 (2004).

[5] J. Brus, F. Kolar, V. Machovic, J. Svitilova, J. NonCrystalline Solids 289, 62 (2001).
[6] C.G. Pantano, A.K. Singh, H.X. Zhang, Journal of Sol-Gel Science and Technology 14, 7 (1999).

[7] H. Miyazaki, Jpn. J. Appl. Phys. 47, 8287 (2008).

[8] J.V. Ryan, C.G. Pantano, J. Vacuum Sc. Techn. A 25, 153 (2007).

[9] J.V. Ryan, C.G. Pantano, J. Phys., Cond. Matter 19, 455205 (2007).

[10] H. Brequel, J. Parmentier, G.D. Sorar, L. Schiffini, S. Enzo, Nanostr. Mater. 11, 721 (1999).

[11] E. Ionescu, B. Papendorf, H.J. Kleebe, F. Poli, K. Muller, R. Riedel, J. Am. Ceramic Soc. 93, 1774 (2010).

[12] E. Ionescu, B. Papendorf, H.J. Kleebe, R. Riedel, J. Am. Ceramic Soc. 93, 1783 (2010).

[13] T.A. Liang, Y.L. Li, D. Su, H.B. Du, J. Am. Ceramic Soc. 30, 2677 (2010).

[14] M. Cerny, P. Glogar, Z. Sucharda, Z. Chlup, J. Kotek, Comp. A, Appl. Sci. Manufac. 40, 1650 (2009).

[15] M. Cerny, P. Glogar, Z. Sucharda, J. Comp. Mater. 43, 1109 (2009).

[16] P. Glogar, M. Cerny, Z. Tolde, Acta Geodyn. Geomater. 4, 27 (2007).

[17] M. Cerny, Z. Sucharda, A. Strachota, Z. Chlup, P. Glogar, accepted in Ceramics-Silikaty.

[18] Z. Chlup, M. Cerny, A. Strachota, V. Kozak, submitted to Plastics, Rubber and Composites.

[19] ISO 14577 Instrumented indentation test for hardness and material parameters (2001).

[20] M.G. Voronkov, J. Organometal. Chem. 557, 143 (1998).

[21] J.C. Kleinert, C.J. Weschler, Analytical Chemistrty $\mathbf{5 2}, 1245$ (1980). 